\title{
The Effect of Anaerobic and Aerobic Fish Sludge Supernatant on Hydroponic Lettuce
}

\author{
Simon Goddek ${ }^{1, *}$, Zala Schmautz ${ }^{2}$, Ben Scott ${ }^{2}$, Boris Delaide ${ }^{3}$, Karel J. Keesman ${ }^{1}$, \\ Sven Wuertz ${ }^{4}$ and Ranka Junge ${ }^{2, *}$ \\ 1 Biobased Chemistry \& Technology, Wageningen University, P.O. Box 17, \\ Wageningen 6700 AA, The Netherlands; karel.keesman@wur.nl \\ 2 Institute for Natural Resource Sciences Gruental, ZHAW Zurich University of Applied Sciences, \\ Waedenswil CH-8820, Switzerland; zala.schmautz@zhaw.ch (Z.S.); scottben@students.zhaw.ch (B.S.) \\ 3 Integrated and Urban Plant Pathology Laboratory, Université de Liège, Avenue Maréchal Juin 13, \\ Gembloux 5030, Belgium; boris.delaide@ulg.ac.be \\ 4 IGB, Ecophysiology and Aquaculture, Müggelseedamm 310, Berlin 12587, Germany; wuertz@igb-berlin.de \\ * Correspondence: simon.goddek@wur.nl (S.G.); ranka.junge@zhaw.ch (R.J.); Tel.: +31-61-122-8251 (S.G.); \\ +41-58-934-5922 (R.J.)
}

Academic Editor: Mike McLaughlin

Received: 12 May 2016; Accepted: 14 June 2016; Published: 21 June 2016

\begin{abstract}
The mobilization of nutrients from fish sludge (i.e., feces and uneaten feed) plays a key role in optimizing the resource utilization and thus in improving the sustainability of aquaponic systems. While several studies have documented the aerobic and anaerobic digestion performance of aquaculture sludge, the impact of the digestate on plant growth has yet to be understood. The present study examines the impact of either an aerobic or an anaerobic digestion effluent on lettuce plant growth, by enriching a mixture of aquaculture and tap water with supernatants from both aerobic and anaerobic batch reactors. The lettuce plants grown in the hydroponic system supplied with supernatant from an anaerobic reactor had significantly better performance with respect to weight gain than both, those in the system where supernatant from the aerobic reactor was added, as well as the control system. It can be hypothesized that this effect was caused by the presence of $\mathrm{NH}_{4}{ }^{+}$as well as dissolved organic matter, plant growth promoting rhizobacteria and fungi, and humic acid, which are predominantly present in anaerobic effluents. This study should therefore be of value to researchers and practitioners wishing to further develop sludge remineralization in aquaponic systems.
\end{abstract}

Keywords: aquaponics; anaerobic digestion; aerobic digestion; hydroponics; sludge; integrated aquaculture; horticulture; bio-fertilizer

\section{Introduction}

A primary concern of aquaponics is the efficient utilization of all nutrients that enter the system. Several studies have documented a high loss of nutrients from the recycling loop via the mechanical water treatment unit as well as unused Recirculating Aquaculture System (RAS)-derived sludge [1-6] that consists of feces and uneaten feed. Consequently, the reuse of sludge is gaining importance and plays a crucial role in the utilization of the supplied nutrients and thereby in reduction of nutrient emissions [2,7]. With respect to the usage of RAS water in hydroponic systems, Jijakli et al. [8] examined whether complementing the RAS water with mineral elements to levels usually targeted in hydroponics improves crop growth. They observed an increased plant growth of the complemented aquaponic solutions by up to $39 \%$ compared with the hydroponic control nutrient solution, which was composed of an equivalent nutrient composition. Their work shows that plants in a highly 
concentrated RAS nutrient solution had better growth. However, their study has only a limited relevance with regard to the impact of aerobic and anaerobic supernatants from fish sludge digestion on plant growth performance.

Although some research was carried out on the impact of domestic sewage and industrial wastes on plant growth [9-11], to date, the impact of aerobically and anaerobically treated RAS-derived sludge on plant growth has not yet been experimentally investigated. Effluents from anaerobic digestion generally have high concentrations of nutrients, as sources of carbon are metabolized preferentially during treatment $[9,11]$. However, most anaerobic effluents are characterized by high chemical oxygen demands (CODs), hydrogen sulfides $\left(\mathrm{H}_{2} \mathrm{~S}\right)$ content, and low dissolved oxygen (DO) concentrations, and thus can be considered phytotoxic. In this case, a post-treatment (e.g., aerobic detoxification) for the anaerobic effluent is required before being directed to the plants [10-12].

The primary aim of this study was to comparatively assess the effect of effluents originating from anaerobic and aerobic batch digesters on to plant growth performance. Even though simple digestion techniques were used that did not exploit the entire potential of both treatments, this study offers some important insights into the role that remineralization practices may play in aquaponic systems with respect to plant growth performance.

\section{Materials and Methods}

\subsection{Experimental Setup}

The experiment was conducted in a greenhouse in Wädenswil from 16 October to 20 November 2015. Three one-cycle aquaponics systems were used for this experiment, each built of a sump, a settling tank, and a biofilter, and three nutrient film technique (NFT) channels (Figure 1) were run in parallel and were planted with 36 lettuce plants (Lactuca sativa yacht variety Salanova ${ }^{\circledR}$ ). The total volume of one system was approximately $400 \mathrm{~L}$. Aeration into the sump and the biofilter was provided via compressed air (AL-80, Alita Industries, Arcadia, CA, USA) and air stones to assure sufficient DO levels as well as proper mixing of biochips in the biofilter. A water pump (Aquarius Universal Eco 4000, Oase, Germany) with an approximate flow rate of $62 \mathrm{~L} / \mathrm{h}$ directed water from the biofilter to the NFT channels. A heater (NEWA Therm pro $250 \mathrm{~W}$, NEWA Tecno Industrial Srl, Loreggia, Italy) was installed in the biofilter maintaining constant temperatures in the system $\left(22 \pm 1.5^{\circ} \mathrm{C}\right)$. No additional lighting was used.

For two months (since July 2015), 4 L of RAS sludge of Nile tilapia culture fed with Hokovit Tilapia Vegi feed were added weekly to two reservoirs. One was constantly aerated and the other one was kept under anaerobic conditions. No additional sludge was added to the reservoirs during the experiment (i.e., after 16 October). To gather the supernatant, the sludge was stirred and centrifuged (Eppendorf Centrifuge 5430, Fisher Scientific, Waltham, MA, USA), 2.5 min at 7000 rcf. Supernatant nutrient composition was determined in the second week of the experiment (Table 1).

At the start of the experiment, all systems were filled with $85 \%$ tap water and $15 \%$ RAS water (Table 1). After that, one liter of supernatant from each aerobic and anaerobic reservoir was added to the aerated system (AER) and unaerated system (ANA) three times a week, respectively. System RAS, acting as a control, was given one liter of RAS water instead.

Table 1. Nutrient composition (mg/L) of the Recirculating Aquaculture System (RAS) and tap water, as well as AER and ANA supernatants, at the beginning of the experiment.

\begin{tabular}{ccccccccccc}
\hline & $\mathbf{C l}$ & $\mathbf{N O}_{2}$ & $\mathbf{N O}_{3}$ & $\mathbf{P O}_{4}$ & $\mathbf{S O}_{4}$ & $\mathbf{N a}$ & $\mathbf{N H}_{4}$ & $\mathbf{K}$ & $\mathbf{C a}$ & $\mathbf{M g}$ \\
\hline AER $^{1}$ Supernatant & 7.9 & 18.5 & 51.8 & 2.7 & 19.7 & 4.4 & 0.7 & 17.2 & 14.2 & 5.1 \\
ANA $^{2}$ Supernatant & 6.1 & 0.0 & 0.0 & 2.7 & 0.5 & 3.6 & 56.4 & 16.3 & 11.7 & 2.5 \\
Tap & 0.3 & 0.0 & 0.2 & 0.0 & 0.8 & 4.9 & 0.0 & 1.0 & 59.8 & 16.3 \\
RAS $^{3}$ & 6.4 & 0.2 & 88.2 & 2.0 & 6.9 & 3.4 & 0.5 & 9.0 & 10.8 & 5.6 \\
\hline
\end{tabular}

${ }^{1}$ supernatant from the aerated reactor; ${ }^{2}$ supernatant from the anaerobic reactor; ${ }^{3}$ water from a recirculating aquaculture system. 


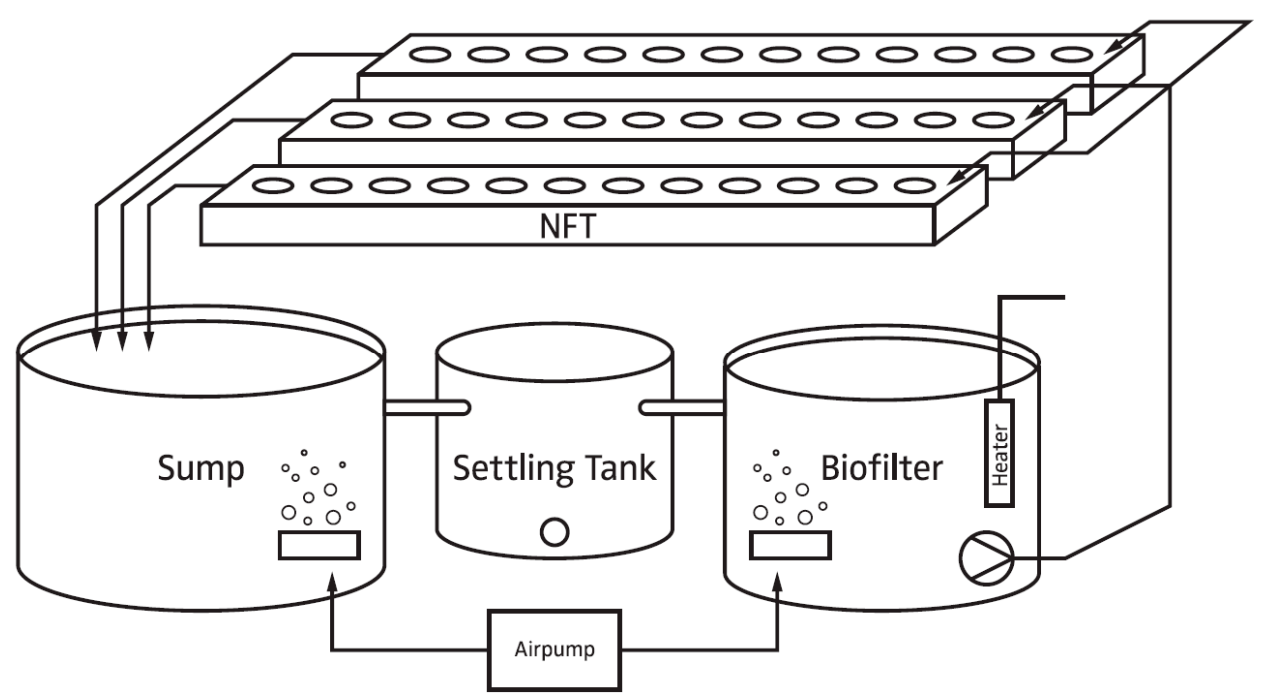

Figure 1. Schematic outline of the experimental systems comprising a sump (max. $280 \mathrm{~L}$ ), a settling tank (70 L), and a biofilter (110 L). Extensive aeration with an air pump ensured reduction of chemical oxygen demands (CODs) as well as optimal dissolved oxygen (DO) in the process water for plant growth. Undiluted AER and ANA supernatants as well as Recirculating Aquaculture System (RAS) water entered the system via the sumps of the respective systems three times a week. Samples for measurements were taken in the sump at least $24 \mathrm{~h}$ after the supernatants or RAS water were added.

\subsection{Supernatant and Water Analysis}

Samples of both aerobic and anaerobic supernatants were taken at the end of the first week of the experiment. Macronutrients $\left(\mathrm{NO}_{2}, \mathrm{NO}_{3}, \mathrm{PO}_{4}, \mathrm{SO}_{4}, \mathrm{NH}_{4}, \mathrm{~K}, \mathrm{Ca}\right.$, and $\left.\mathrm{Mg}\right)$ and micronutrients $(\mathrm{Cl}$ and $\mathrm{Na}$ ) were analyzed with an IC (930 Compact IC Flex, Metrohm, Zofingen, Switzerland) and other micronutrients (B, Cu, Fe, Mn, Mo, and $\mathrm{Zn}$ ) with an ICP-AES (Varian Vista AX CCD Simultaneous ICP-AES, Agilent Technologies, Santa Clara, CA, USA). Prior to these analyses, homogenous anaerobic and aerobic sludge was taken from both reservoirs and centrifuged for $7.5 \mathrm{~min}$ at $7000 \mathrm{rcf}$ and filtrated with $0.22 \mu \mathrm{m}$ syringe filters (Table 1 ).

The initial nutrient concentration within the three aquaponics systems was derived from the initial RAS and tap water values that were analyzed with the IC Flex 930 Metrohm (Table 2). The same equipment was used to determine the water nutrient concentration in the sump of each system three times (on Days 19, 27, and 36) throughout the 5-week experiment. These samples were taken from the sump one day after tap water was added to compensate for water losses due to evapotranspiration to make sure the water was well mixed. $\mathrm{DO}, \mathrm{pH}, \mathrm{EC}$, and temperature were measured twice a week with a portable multi-parameter meter (HQ40d Portable Multi-Parameter Meter, Hach Lange, Düsseldorf, Germany).

\subsection{Lettuce}

Six weeks before the beginning of the experiment, single pelleted lettuce was seeded into rock wool. The initial weight of the lettuce seedlings when transferred into the aquaponic system was $10.3 \mathrm{~g} \pm 0.2 \mathrm{~g}$, which was determined by pre-weighting the rock wool. After 36 days of cultivation, nine lettuce plants (front, middle, back) laid down in advance were sampled from each system for further analysis. The shoots were separated from the roots by cutting it just above the rockwool block, whereas the roots were cut off at the bottom side of the rockwool block. The shoots were dried at $80^{\circ} \mathrm{C}$ for $48 \mathrm{~h}$ for dry weight determination. The content of $\mathrm{P}, \mathrm{S}, \mathrm{Mg}, \mathrm{Ca}, \mathrm{K}, \mathrm{Fe}, \mathrm{Cu}, \mathrm{Mn}, \mathrm{Zn}, \mathrm{B}, \mathrm{Mo}$, and $\mathrm{Na}$ was determined with an ICP-OES (5100 VDV ICP-OES, Agilent Technologies, Santa Clara, CA, USA) after the dried biomass was pulverized and acid mineralized. The $\mathrm{C}, \mathrm{H}$, and $\mathrm{N}$ content was measured 
on three samples of dry lettuce plants per system using an elemental analyzer (TruSpec CHN Macro Analyzer, LECO, Saint Joseph, MI, USA).

\subsection{Statistical Analysis}

Data are presented as mean of $n$ replicates. Analysis of statistical significance was conducted in $\mathrm{R}$ software [13], using analysis of variance (ANOVA) test and post hoc multiple comparison. Here, the parametric Tukey's HSD test $(p<0.05)$ was performed.

\section{Results \& Discussion}

During the experiment DO levels in the sump and the recorded water temperatures were stable (Table 2). Even though all three systems were started with the same initial mix of tap water with RAS outflow, the EC in the sump of System AER was initially higher than in the other two sumps (Figure 2a; Table 2). This difference is probably due to the fact that the systems were used for experiments before. $\mathrm{Ca}$ and $\mathrm{K}$ residues in both, the pipes, and the biofiltration media might have caused these slightly higher values. An indication for that is the higher Ca and K content in System AER (see Figure 3d,e), while the $\mathrm{Ca}$ and $\mathrm{K}$ concentrations of both supernatant solutions did not reveal similar differences (Figure 4; Table 1). The $\mathrm{pH}$ values during the trial did not show major symmetric differences in the three systems and fluctuated between 8.1 and 8.7 (Figure 2b; Table 2).

Table 2. Means and standard deviation of main measured water parameters during the 35 days of the experiment $(n=11)$.

\begin{tabular}{cccc}
\hline & System AER $^{\mathbf{1}}$ & System ANA $^{2}$ & System RAS $^{3}$ (Control) \\
\hline $\mathrm{DO}^{4}(\mathrm{mg} / \mathrm{L})$ & $8.5 \pm 0.3$ & $8.4 \pm 0.3$ & $8.6 \pm 0.3$ \\
Water Temperatures $\left({ }^{\circ} \mathrm{C}\right)$ & $22.9 \pm 1.3$ & $22.6 \pm 1.6$ & $21.2 \pm 1.6$ \\
$\mathrm{EC}^{5}(\mu \mathrm{S} / \mathrm{cm})$ & $895.5 \pm 59.8$ & $766.6 \pm 41.2$ & $725.1 \pm 49.2$ \\
$\mathrm{pH}$ & $8.4 \pm 0.2$ & $8.5 \pm 0.2$ & $8.5 \pm 0.2$ \\
\hline
\end{tabular}

1 supernatant from the aerated reactor; ${ }^{2}$ supernatant from the anaerobic reactor; ${ }^{3}$ water from a recirculating aquaculture system; ${ }^{4}$ dissolved oxygen; ${ }^{5}$ electrical conductivity.

(a)

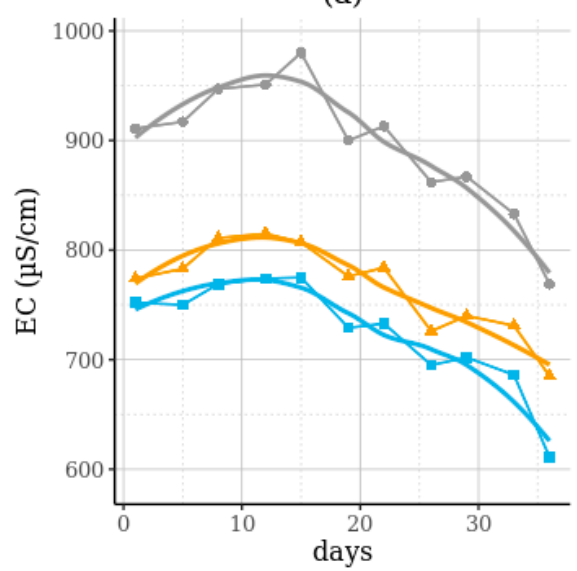

(b)

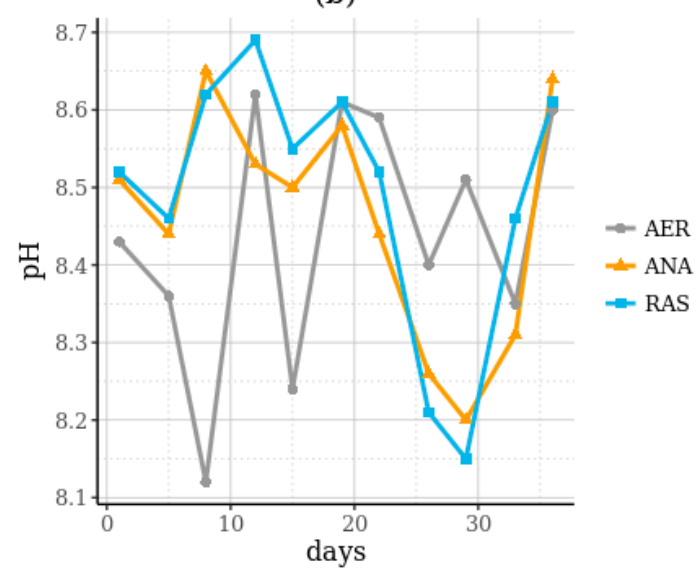

Figure 2. Variation of (a) electric conductivity (EC) and (b) $\mathrm{pH}$ (on a scale from 8.1 to 8.7 ) in the sump of the aerobic (AER), anaerobic (ANA), and RAS systems over the 35-day experimental period. 
(a)

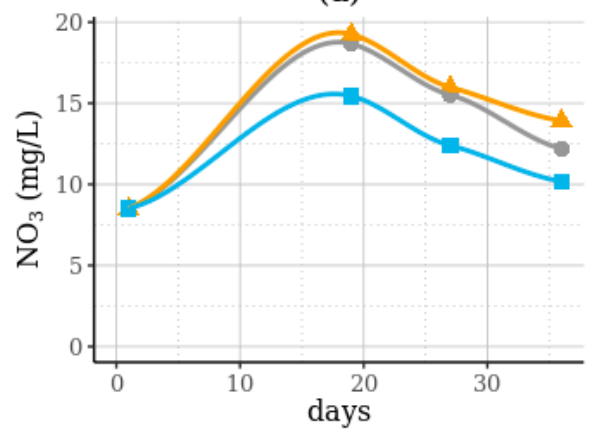

(c)

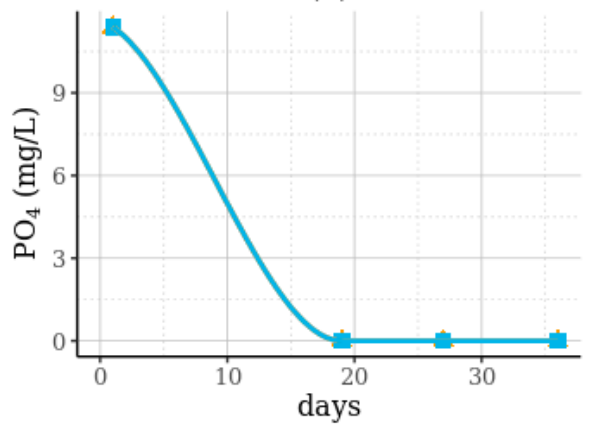

(e)

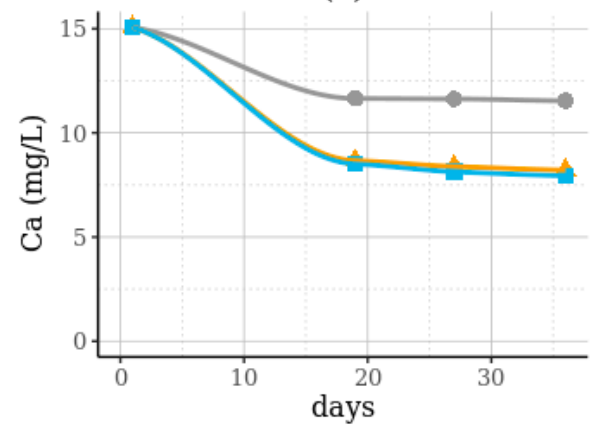

(b)

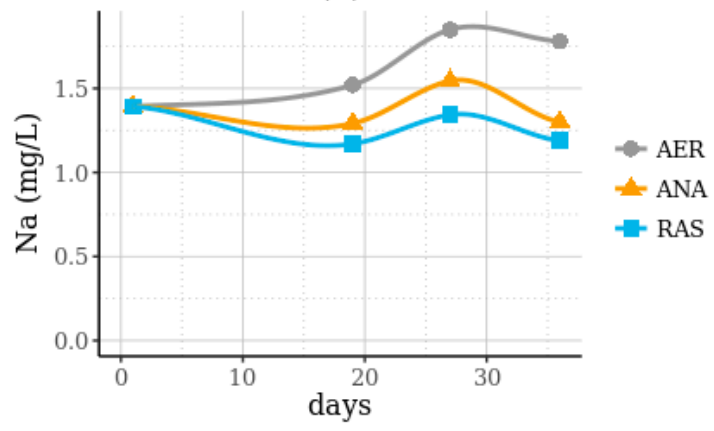

(d)

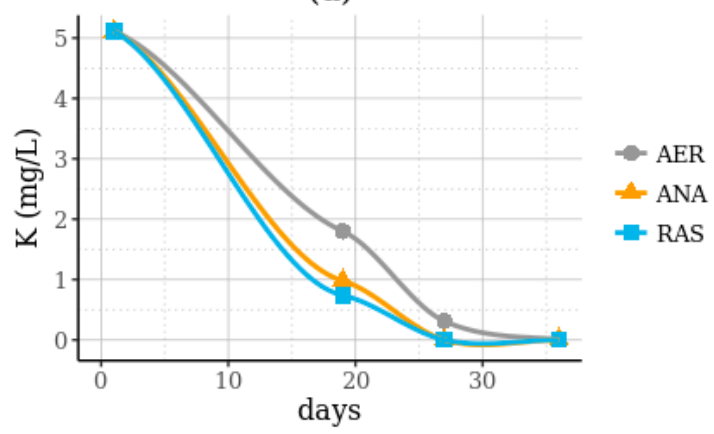

(f)

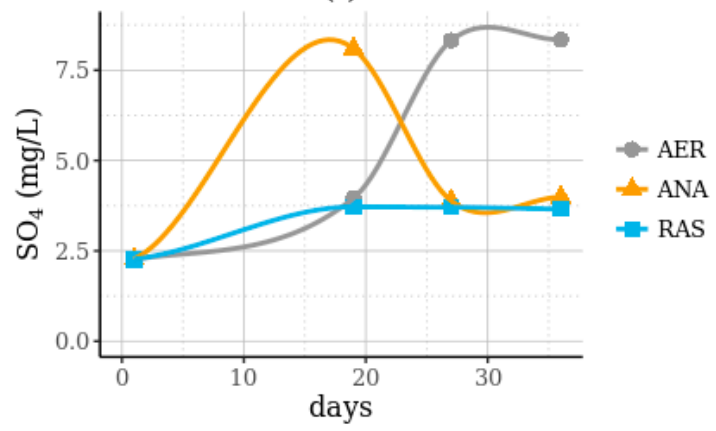

Figure 3. Concentrations of (a) nitrate; (b) sodium; (c) phosphate; (d) potassium; (e) calcium; and (f) sulfate in the sump of the aerobic (AER), anaerobic (ANA), and RAS systems over the 35-day experimental period.

Figures 4 and 5 show the macro- and micronutrient concentrations in the aerobic and the anaerobic supernatant at the beginning of the experiment. It must be mentioned that, due to ICP analysis, we do not have any information about the form of the analyzed metals (i.e., to what degree they are chelated). The results in Figure 5 show an increased manganese $(\mathrm{Mn})$ concentration in the aerobic supernatant. According to Resh [14], the optimum Mn in hydroponic solutions ranges between 0.5 and $0.8 \mathrm{mg} / \mathrm{L}$, which is in compliance with the concentration in the aerobic supernatant before being diluted in the experimental system. Upon dilution, deficiencies of Mn would be expected in both systems, but to a higher degree in System ANA. Micronutrients in the RAS water were not measured. 


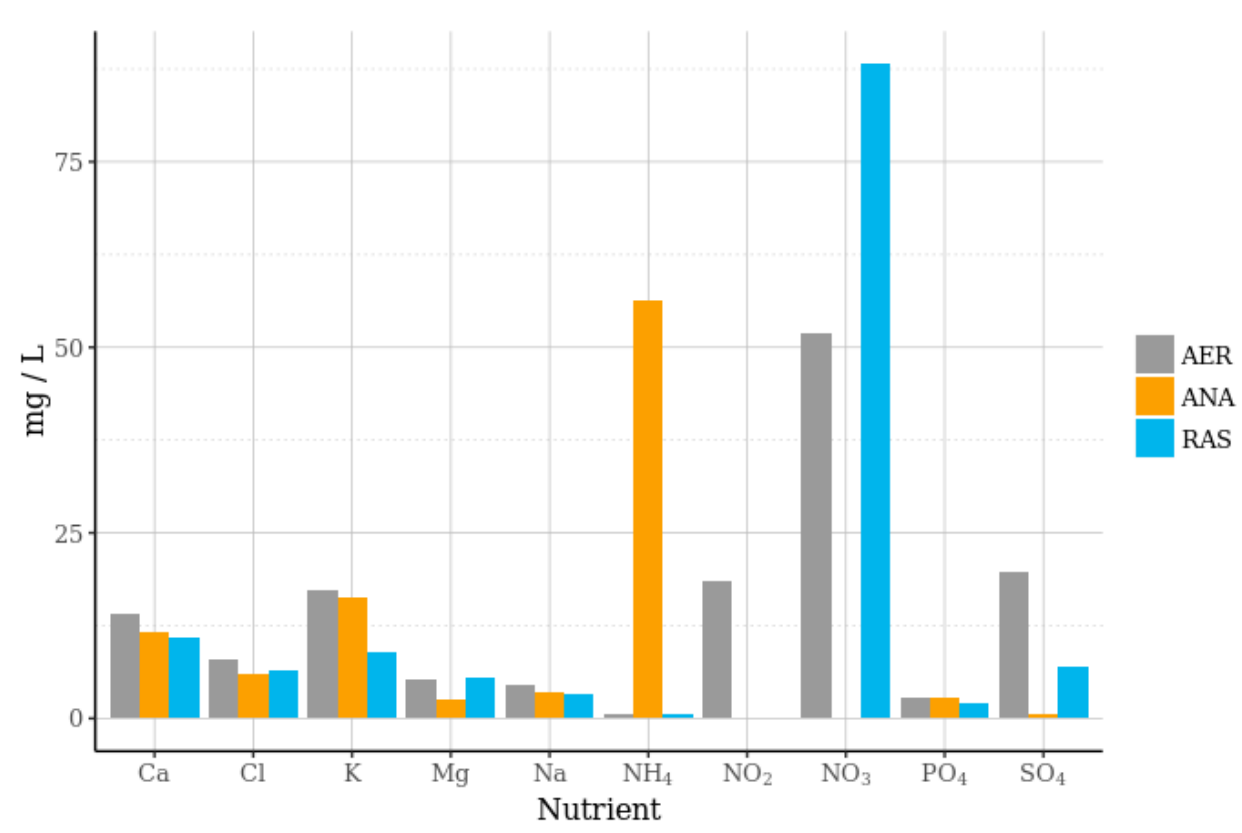

Figure 4. Nutrient composition of both undiluted AER and ANA supernatants as well as Recirculating Aquaculture System (RAS) water at the beginning of the experiment.

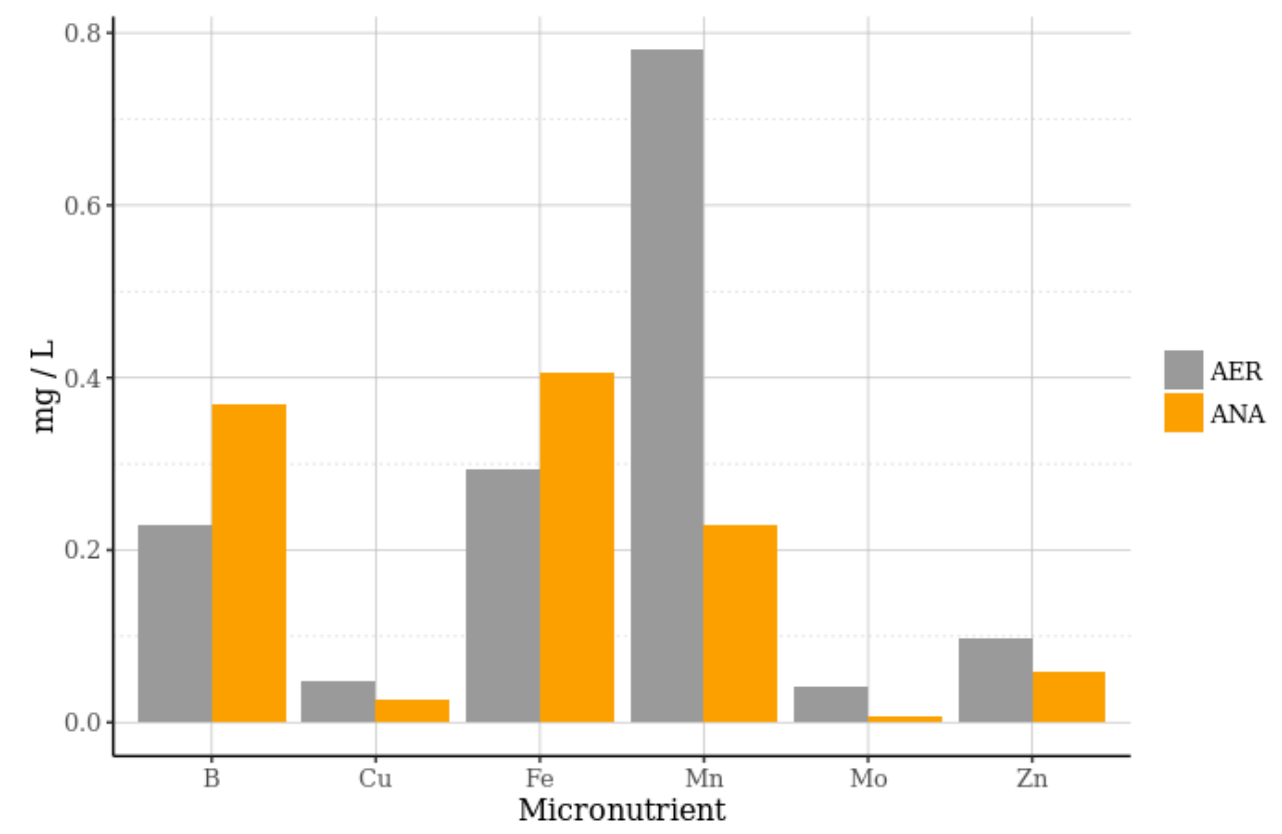

Figure 5. Micronutrients of the undiluted AER and ANA supernatant additives at the beginning of the experiment.

The observed AER and ANA supernatant nutrient values (Figures 4 and 5) were relatively stable throughout the experiment. However, four days before the end of the experiment, we observed an unexplainable drop in the redox potential in the aerobic reservoir-the sludge blackened within. Additional IC data showed that only $\mathrm{NO}_{3}$ and $\mathrm{NO}_{2}$ levels were affected. The corresponding drop in $\mathrm{NO}_{3}$ concentration can be seen in Figure 3a, where the graphs of System AER and ANA are not congruent anymore within the last couple of days. Apart from the different forms of nitrogen, the remineralization performance of both reservoirs was similar. However, we hypothesize that a better remineralization performance can be expected when using other methods of anaerobic digestion 
such as upflow anaerobic sludge blanket (UASB) treatments with granular sludge [15-17], including a longer start-up time that ensures the presence of sufficient anaerobic bacteria, which tend to grow slower than aerobic bacteria.

Another interesting finding is that $\mathrm{SO}_{4}$ was present in the sump of System ANA (Figure $3 \mathrm{f}$ ) at the beginning of the experiment, but was not found in the anaerobic supernatant (Figure 4). These results show that the aerobic remineralization performance was slightly more effective than the anaerobic treatment. It can clearly be seen that the main nitrogen species in RAS water was $\mathrm{NO}_{3}$, compared with the aerobic and especially the anaerobic supernatant additives (Figure 4). Here, in the anaerobic supernatant, $\mathrm{NO}_{3}$ was already reduced to $\mathrm{NH}_{4}$. It should also be mentioned that the aerobic effluent contained almost three times as much $\mathrm{SO}_{4}$ than the RAS water, whereas the anaerobic effluent did not contain any $\mathrm{SO}_{4}$ at the time the sample was taken. This, however, can be explained by the fact that sulfate gets converted to $\mathrm{H}_{2} \mathrm{~S}$ - which has not been measured-under anaerobic conditions [18]. This assumption is supported by Krayzelova et al. [19], who report oxidation of $\mathrm{H}_{2} \mathrm{~S}$ to $\mathrm{SO}_{4}$ under aerobic conditions. Thereby, $\mathrm{H}_{2} \mathrm{~S}$, which is hazardous to plants, is eliminated. Congruently, in our study, a $\mathrm{SO}_{4}$ peak was observed on Day 18 (Figure 3f). The decrease of $\mathrm{SO}_{4}$ in System ANA cannot be directly explained, but we hypothesize that bacteria and fungi might have stimulated its uptake by the plants. Furthermore, $\mathrm{SO}_{4}$ accumulated to a concentration of about $8 \mathrm{mg} / \mathrm{L}$ in System AER due to oxidation of all sulfur components.

Concentrations of six nutrients- $\mathrm{NO}_{3}, \mathrm{Na}, \mathrm{PO}_{4}, \mathrm{~K}, \mathrm{Ca}$, and $\mathrm{SO}_{4}$ - within the Systems AER and ANA over the experimental period of 35 days are shown in Figure 4 . In contrast to the anaerobic supernatant, $\mathrm{NH}_{4}$ was not found in any of the systems, which is plausible, as aeration assures the oxidation of $\mathrm{NH}_{4}$ to $\mathrm{NO}_{3}$.

Unexpectedly, lettuce had better growth in System ANA (Figure 6). The opposite effect was observed with regard to the root growth of the plants (Figure 7), leading to a higher shoot-to-root ratio of System ANA (2.14) compared with Systems AER (1.39) and RAS (1.30). With respect to the general nutrient uptake of plants, Liebig's law of the minimum must be considered, which indicates that the nutrient that is least present determines the maximum growth rate. Still, Figures $3-5$ do not indicate that there was any nutrient that was not available in System AER but present in System ANA. However, Lynch et al. [20] report that an increased shoot-to-root ratio is particularly marked with an increased $\mathrm{N}$ supply, which was not observed in our experiment.

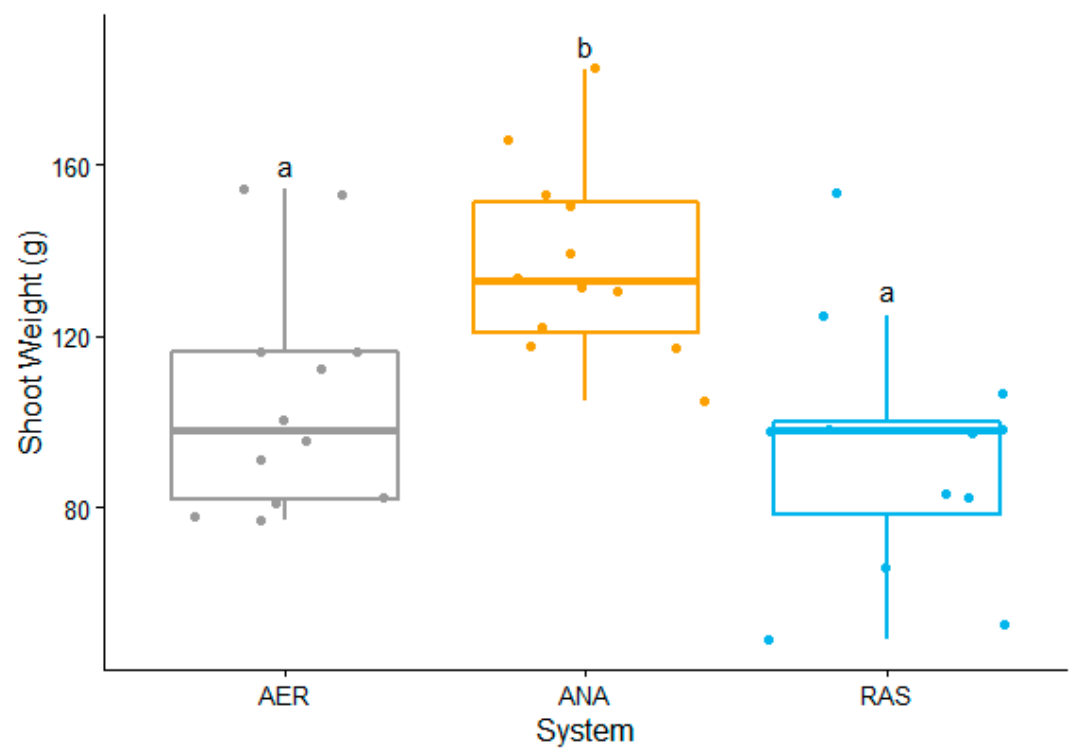

Figure 6. Lettuce shoot fresh weight in the aerobic (AER), anaerobic (ANA), and RAS systems after 35 days. Different letters indicate significant differences (Tukey's HSD, $n=12, p<05$ ). Descriptive statistical data of this box plot can be found in Table 3 . 


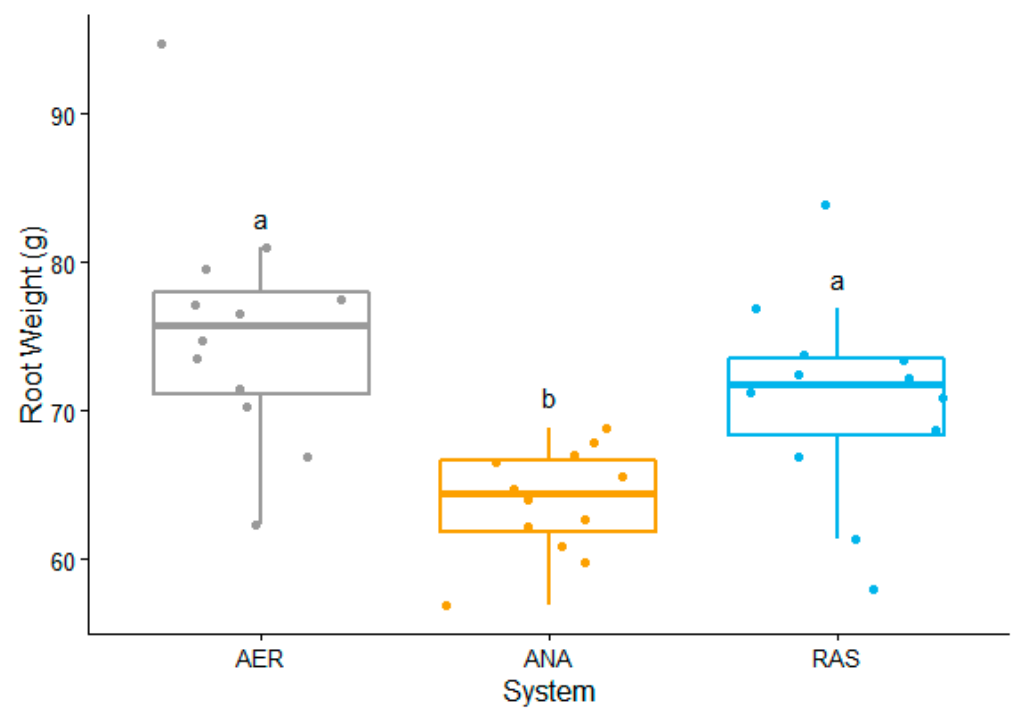

Figure 7. Lettuce root fresh weight in the aerobic (AER), anaerobic (ANA), and RAS systems after 35 days. Different letters indicate significant differences (Tukey's HSD, $n=12, p<05$ ). Descriptive statistical data of this box plot can be found in Table 3.

Table 3. Descriptive statistical data for shoot and root fresh weight in $\mathrm{g}$.

\begin{tabular}{ccccccc}
\hline & \multicolumn{3}{c}{ Shoots } & \multicolumn{3}{c}{ Roots } \\
\cline { 2 - 7 } & System AER & System ANA & System RAS & System AER & System ANA & System RAS \\
\hline Min. & 77.1 & 105.0 & 49.0 & 62.3 & 56.9 & 58.0 \\
1st Quantile & 81.8 & 120.9 & 78.2 & 71.1 & 61.9 & 68.3 \\
Median & 97.8 & 132.6 & 97.7 & 75.7 & 64.4 & 71.8 \\
Mean & 104.8 & 137.4 & 92.4 & 75.5 & 63.9 & 70.8 \\
3rd Quantile & 116.4 & 151.1 & 100.2 & 78.0 & 66.6 & 73.5 \\
Max. & 154.4 & 182.5 & 153.5 & 94.7 & 68.8 & 83.9 \\
\hline
\end{tabular}

There are several plausible explanations for the increased shoot-to-root ratio observed in the system ANA. Firstly, the utilization of $\mathrm{NH}_{4}$ provided by the ANA is energetically more favorable for most plants, since in most cases $\mathrm{NO}_{3}$ has to be converted to $\mathrm{NH}_{4}$ by the plant [18]. Moreover, the uptake of one of these two $\mathrm{N}$-sources also seems to be $\mathrm{pH}$-dependent. Jones [21] reports that plants prefer $\mathrm{NO}_{3}$ in acidic environments, whereas $\mathrm{NH}_{4}$ is the favored nitrogen source in alkaline environments. Since the $\mathrm{pH}$ values in the three systems were between 8.1 and $8.7, \mathrm{NH}_{4}$ is the preferred nitrogen source for the plants. In addition, several authors [21-23] have suggested or reported that $\mathrm{NH}_{4}$ boosts plant growth if it represents a small proportion of the nitrogen available. For instance, it has been observed that a proportion of $30 \%$ of $\mathrm{NH}_{4}$ increased the lettuce harvest in a dripping irrigation system [24]. This is in accordance with Sonneveld [22] and Jones [21], who state that a supply of $10 \%-15 \%$ and $25 \%$ of $\mathrm{NH}_{4}$, respectively, is optimal for most plants grown on substrates. Contrary to standing aerated systems, even $5 \%$ of $\mathrm{NH}_{4}$ could stimulate $\mathrm{NO}_{3}$ uptake in constantly operated systems like the ones used in this experiment. This is attributed to the fact that the specific nitrogen uptake is water-flow-dependent. That is, the lower the $\mathrm{NH}_{4}$ concentration, the higher the flow should be [21]. In our case, the $\mathrm{NH}_{4}$ content of the anaerobic supernatant was high (Figure 4) and could have contributed to an increased uptake. However, since the system was highly aerated, nitrification must have occurred very fast. Measurements of the water were always taken one day after the supernatants were added. This could be the reason why we had not measured $\mathrm{NH}_{4}$ in the system. Secondly, the sodium level in ANA was slightly lower (Figure $3 \mathrm{~b}$ ). The sodium levels most likely did not slow down the growth performance of the lettuce plants, as the concentration was far below the salinity threshold $[25,26]$. 
Even though $\mathrm{pH}$ values between 8.2 and 8.7 were measured in the sump of System ANA, the possibility that the $\mathrm{pH}$ in the rhizosphere of System ANA was temporarily lower than in the other two systems cannot be excluded. This could have been caused by the addition of the ANA supernatant. To restore the electrochemical balance in root cells and nutrient solution, the uptake of cations (i.e., $\mathrm{NH}_{4}$ ) is balanced by a release of protons $\left(\mathrm{H}^{+}\right)$that decrease the rhizosphere $\mathrm{pH}$ [27-30]. A lower $\mathrm{pH}$ than the observed one in the sump, most likely would have caused an increase in nutrient uptake. The uptake of most macronutrients is optimal between $\mathrm{pH}$ values 6 and 8 , whereas the uptake of micronutrients is better below pH 6 [31,32]. In commercial hydroponic systems, the $\mathrm{pH}$ is typically around 5.5 and 6.0 [33], which is much lower than the $\mathrm{pH}$ values reported here.

With respect to the plant growth performance, there are several arguments that could explain an opposite effect. $\mathrm{SO}_{4}$ concentration could have restricted the growth of lettuce in System AER. However, just like the temporary $\mathrm{H}_{2} \mathrm{~S}$ availability in system $\mathrm{ANA}$, the observed $\mathrm{SO}_{4}$ concentration is much lower than recommended for hydroponic practice [33,34]. Another factor that decreases plant growth is a high COD level [9], which is much higher in anaerobic effluents than in aerobic effluents. Since our systems were highly aerated and showed a saturated DO level over the entire experimental period, we can reject this assumption. Besides COD, volatile fatty acids (VFAs) are present in high concentrations in anaerobic effluents, inhibiting shoot and root growth [35]. All these factors are enforced in low $\mathrm{pH}$ environments, which was not the case in our experiment with $\mathrm{pH}$ between 8.1 and 8.7 in the sump.

Another factor that could explain the results is that the anaerobic effluent contained substances that promote the shoot growth and nutrient uptake (Table 1). Literature indicates that these substances could be (1) dissolved organic matter (DOM) and (2) plant growth promoting rhizobacteria and / or fungi (PRPR and/or PGPF). Haghighi [36] showed that the addition of humic acid to a hydroponic solution improved $\mathrm{N}$ metabolism and photosynthesis activity of the lettuce plants, which led to a higher yield. These findings are supported by Ruzzi and Aroca [37], who state that PGPR can release phytohormones or induce hormonal changes within plants that stimulate plant cell elongation and division. Even though the results show better growth in the ANA treatment, this study did not look into human pathogens that might occur on the roots and leaves. This question could be addressed with metagenomic analyses of the present microbiota.

\section{Conclusions}

This study examined the differences in lettuce plant growth performance comparing the addition of anaerobic and aerobic sludge effluents and RAS effluent to the hydroponic system. Our findings provide strong empirical confirmation that anaerobic effluents generally have a positive impact on plant growth. We hypothesize that the enhanced growth of lettuce in System ANA is a result of the added $\mathrm{NH}_{4}$ from the anaerobic fish sludge supernatant (Figure 4), which improves the nutrient uptake and at least temporarily lowers the $\mathrm{pH}$ in the rhizosphere that contributes to the same effect. Moreover, DOM, PRPR/PGPF, and humic acid that occur in anaerobic effluents could play an important role in the lettuce's nutrient uptake and utilization. Although the scope in this study was limited in terms of regular measurements of the supernatant composition that might have changed within this period, the study clearly indicates enhanced growth performance when exposing the plants to anaerobic supernatant enriched RAS water. Furthermore, anaerobic digestion generally needs a start-up period of several months to reach full efficiency, which was not fully realized. Further studies should focus on a better understand of the factors that led to these results, as well as the determination of the optimal dilution of anaerobic supernatant with RAS water. Within the framework of decoupled aquaponic systems, this information is encouraging with regard to the development and implementation of anaerobic nutrient recycling from sludge, improving resource utilization and reducing nutrient emissions in aquaponics. It would also be interesting to see whether a cumulative effect can be observed when exposing plants to a hydroponic solution that contains ANA supernatant as well as RAS water. 
Acknowledgments: The authors would like to acknowledge networking and publication support by COST Action FA1305-The EU Aquaponics Hub-Realising Sustainable Integrated Fish and Vegetable Production for the EU as well as ZHAW, Institute of Natural Resource Sciences in Wädenswil for both funding this publication and providing research facilities. Furthermore, a big "Dankeschön" to Aquaponik Manufaktur GmbH for co-funding this publication.

Author Contributions: Simon Goddek, Ranka Junge, and Zala Schmautz conceived and designed the experiments, which were performed at the Zurich University of Applied Sciences, Wädenswil, Switzerland; Simon Goddek, Benjamin Scott, and Zala Schmautz performed the experiments; Simon Goddek and Karel Keesman analyzed the data; Simon Goddek, Sven Wuertz, Boris Delaide, Zala Schmautz, and Ranka Junge wrote the paper.

Conflicts of Interest: The authors declare no conflict of interest.

\section{Appendix A}

Table A1. Mean values ( \pm SD) of nutrient content (in $\mathrm{mg} / \mathrm{g}$ ) of the lettuce shoots of each system.

\begin{tabular}{cccc}
\hline Macronutrient & System AER & System ANA & System RAS \\
\hline N & $53.7 \pm 0.1^{\mathrm{a}}$ & $54.6 \pm 0.4^{\mathrm{a}}$ & $56.7 \pm 0.5^{\mathrm{b}}$ \\
$\mathrm{C}$ & $345.8 \pm 6.9^{\mathrm{a}}$ & $338.8 \pm 7.2^{\mathrm{a}}$ & $361.0 \pm 8.2^{\mathrm{b}}$ \\
$\mathrm{H}$ & $42.9 \pm 3.1^{\mathrm{a}}$ & $42.9 \pm 2.0^{\mathrm{a}}$ & $40.0 \pm 3.2^{\mathrm{a}}$ \\
$\mathrm{P}$ & $201.3 \pm 0.7^{\mathrm{a}}$ & $329.5 \pm 1.3^{\mathrm{b}}$ & $191.7 \pm 1.10^{\mathrm{c}}$ \\
$\mathrm{K}$ & $1473.33 \pm 4.5^{\mathrm{a}}$ & $2134.67 \pm 4.0^{\mathrm{b}}$ & $1437.7 \pm 4.16^{\mathrm{c}}$ \\
$\mathrm{Ca}$ & $1757.00 \pm 1.7^{\mathrm{a}}$ & $2504.33 \pm 2.3^{\mathrm{b}}$ & $1878.7 \pm 1.46^{\mathrm{c}}$ \\
$\mathrm{Mg}$ & $324.20 \pm 0.8^{\mathrm{a}}$ & $502.20 \pm 1.7^{\mathrm{b}}$ & $395.6 \pm 0.78^{\mathrm{c}}$ \\
$\mathrm{S}$ & $202.47 \pm 0.7^{\mathrm{a}}$ & $215.73 \pm 0.8^{\mathrm{b}}$ & $199.5 \pm 0.36^{\mathrm{c}}$ \\
$\mathrm{Na}$ & $135.33 \pm 0.3^{\mathrm{a}}$ & $306.47 \pm 0.9^{\mathrm{b}}$ & $231.9 \pm 0.46^{\mathrm{c}}$ \\
\hline
\end{tabular}

Different letters indicate significant differences (ANOVA with Tukey's HSD post hoc test, $p<0.05, n=3$ ).

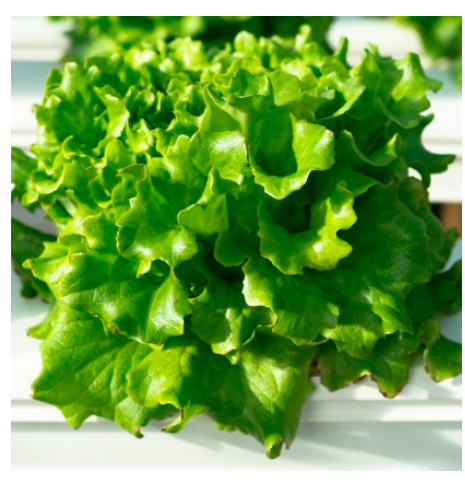

(a)

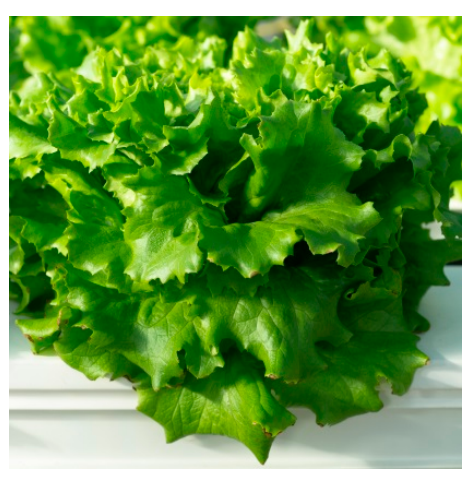

(b)

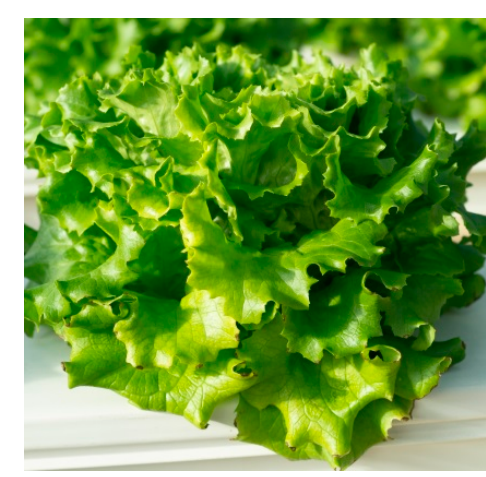

(c)

Figure A1. Close-up images of lettuce grown in (a) System AER, (b) System ANA, and (c) System RAS.

\section{References}

1. Neto, R.M.; Ostrensky, A. Nutrient load estimation in the waste of Nile tilapia Oreochromis niloticus (L.) reared in cages in tropical climate conditions. Aquac. Res. 2013, 46, 1309-1322. [CrossRef]

2. Goddek, S.; Espinal, C.; Delaide, B.; Jijakli, H.M.; Schmautz, Z.; Wuertz, S.; Keesman, K.J. Navigating towards Decoupled Aquaponic Systems: A System Dynamic Design Approach. 2016. unpublished work.

3. Timmons, M.B.; Ebeling, J.M. Recirculating Aquaculture, 3rd ed.; Ithaca Publishing Company LLC: Ithaca, NY, USA, 2013.

4. Rafiee, G.; Saad, C.R. Nutrient cycle and sludge production during different stages of red tilapia (Oreochromis sp.) growth in a recirculating aquaculture system. Aquaculture 2005, 244, 109-118. [CrossRef]

5. Shnel, N.; Barak, Y.; Ezer, T.; Dafni, Z.; van Rijn, J. Design and performance of a zero-discharge tilapia recirculating system. Aquac. Eng. 2002, 26, 191-203. [CrossRef] 
6. Suzuki, Y.; Maruyama, T.; Numata, H.; Sato, H.; Asakawa, M. Performance of a closed recirculating system with foam separation, nitrification and denitrification units for intensive culture of eel: Towards zero emission. Aquac. Eng. 2003, 29, 165-182. [CrossRef]

7. Monsees, H.; Keitel, J.; Kloas, W.; Wuertz, S. Potential reuse of aquacultural waste for nutrient solutions in aquaponics. In Oral presentation at Aquaculture Europe; Aquaculture Europe: Rotterdam, The Netherlands, 2015.

8. Jijakli, M.H.; Delaide, B.; Gott, J. Plant production capacity and nutrient mass balance in the PAFF Box, an urban aquaponics module: Preliminary findings. 2016. submitted for publication.

9. Krishnasamy, K.; Nair, J.; Bäuml, B. Hydroponic system for the treatment of anaerobic liquid. Water Sci. Technol. 2012, 65, 1164-1171. [CrossRef] [PubMed]

10. Penetra, R.; Reali, M.; Foresti, E.; Campos, J. Post-treatment of effluents from anaerobic reactor treating domestic sewage by dissolved-air flotation. Water Sci. Technol. 1999, 40, 137-143. [CrossRef]

11. Salminen, E.; Rintala, J.; Härkönen, J.; Kuitunen, M.; Högmander, H.; Oikari, A. Anaerobically digested poultry slaughterhouse wastes as fertiliser in agriculture. Bioresour. Technol. 2001, 78, 81-88. [CrossRef]

12. De Lemos Chernicharo, C.A. Anaerobic Reactors, 4th ed.; IWA Publishing: New Delhi, India, 2007.

13. R Core Team. R: A Language and Environment for Statistical Computing; R Foundation for Statistical Computing: Vienna, Austria, 2012.

14. Resh, H.M. Hydroponic Food Production: A Definite Guidebook for the Advanced Home Gardener and the Commercial Hydroponic Grower, 7th ed.; CRC Press: London, UK, 2013.

15. Mirzoyan, N.; McDonald, R.C.; Gross, A. Anaerobic Treatment of Brackishwater Aquaculture Sludge: An Alternative to Waste Stabilization Ponds. J. World Aquac. Soc. 2012, 43, 238-248. [CrossRef]

16. Mirzoyan, N.; Gross, A. Use of UASB reactors for brackish aquaculture sludge digestion under different conditions. Water Res. 2013, 47, 2843-2850. [CrossRef] [PubMed]

17. Suhr, K.I.; Letelier-Gordo, C.O.; Lund, I. Anaerobic digestion of solid waste in RAS: effect of reactor type on the biochemical acidogenic potential (BAP) and assessment of the biochemical methane potential (BMP) by a batch assay. Aquac. Eng. 2015, 65, 65-71. [CrossRef]

18. Gangagni Rao, A.; Krishna Prasad, K.; Venkata Naidu, G.; Chandrashekar Rao, N.; Sarma, P.N. Removal of sulfide in integrated anaerobic?aerobic wastewater treatment system. Clean Technol. Environ. Policy 2003, 6, 66-72. [CrossRef]

19. Krayzelova, L.; Bartacek, J.; Díaz, I.; Jeison, D.; Volcke, E.I.P.; Jenicek, P. Microaeration for hydrogen sulfide removal during anaerobic treatment: A review. Rev. Environ. Sci. Bio/Technol. 2015, 14, 703-725. [CrossRef]

20. Lynch, J.; Marschner, P.; Rengel, Z. Effect of Internal and External Factors on Root Growth and Development. In Marschner's Mineral Nutrition of Higher Plants; Marschner, P., Ed.; Elsevier Ltd: London, UK, 2012; pp. 331-346.

21. Jones, B.J. Hydroponics - A Practical Guide for the Soilless Grower, 2nd ed.; CRC Press: Boca Raton, FL, USA, 2005.

22. Sonneveld, C. Composition of nutrient solutions. In Hydroponic Production of Vegetables and Ornamentals; Embryo Publisher: Athens, Greece, 2002; pp. 179-2010.

23. Marschner, H. Marschner's Mineral Nutrition of Higher Plants; Elsevier: London, UK, 2012.

24. Savvas, D.; Passam, H.C.; Olympios, C.; Nasi, E.; Moustaka, E.; Mantzos, N.; Barouchas, P. Effects of Ammonium Nitrogen on Lettuce Grown on Pumice in a Closed Hydroponic System. HortScience 2006, 41, 1667-1673.

25. Stofberg, S.F.; Klimkowska, A.; Paulissen, M.P.C.P.; Witte, J.-P.M.; van der Zee, S.E.A.T.M. Effects of salinity on growth of plant species from terrestrializing fens. Aquat. Bot. 2015, 121, 83-90. [CrossRef]

26. Hill, S.; Abaidoo, R.; Miyasaka, S. Sodium Chloride Concentration Affects Early Growth and Nutrient Accumulation in Taro. HortScience 1998, 33, 1153-1156.

27. Neumann, G.; Römheld, V. Rhizosphere Chemistry in Relation to Plant Nutrition. In Marschner's Mineral Nutrition of Higher Plants2; Marschner, P., Ed.; Elsevier Ltd.: London, UK, 2012; pp. 347-368.

28. Dudal, R.; Roy, R.N. Integrated Plant Nutrition Systems: Report of an Expert Consultation, Rome, Italy, 13-15 December 1993; Food \& Agriculture Org.: Roma, Italy, 1995.

29. Silber, A.; Yones, L.B.; Dori, I. Rhizosphere $\mathrm{pH}$ as a result of nitrogen levels and $\mathrm{NH}_{4} / \mathrm{NO}_{3}$ ratio and its effect on zinc availability and on growth of rice flower (Ozothamnus diosmifolius). Plant Soil 2004, 262, $205-213$. [CrossRef]

30. Marschner, H. Mineral Nutrition of Higher Plants; Academic Press: London, UK, 1986. 
31. Lucas, R.E.; Davis, J.F. Relationships between $\mathrm{pH}$ values of organic soils and availabilities of 12 plant nutrients. Soil Sci. 1961, 92, 177-182. [CrossRef]

32. Polomski, R.F. South Carolina Master Gardener Training Manual; Clemson University: Clemson, SC, USA, 2007.

33. Resh, H.M. Hydroponic Food Production: A Definitive Guidebook for the Advanced Home Gardener and the Commercial Hydroponic Grower; CRC Press: Boca Raton, FL, USA, 2012.

34. Sonneveld, C.; Voogt, W. Nutrient Management in Substrate Systems. In Plant Nutrition of Greenhouse Crops; Springer Netherlands: Berlin, Germany, 2009; pp. 277-312.

35. Pang, J.; Cuin, T.; Shabala, L.; Zhou, M.; Mendham, N.; Shabala, S. Effect of secondary metabolites associated with anaerobic soil conditions on ion fluxes and electrophysiology in barley roots. Plant Physiol. 2007, 145, 266-276. [CrossRef] [PubMed]

36. Haghighi, M. The effect of humic and glutamic acids in nutrient solution on the $\mathrm{N}$ metabolism in lettuce. J. Sci. Food Agric. 2012, 92, 3023-3028. [CrossRef] [PubMed]

37. Ruzzi, M.; Aroca, R. Plant growth-promoting rhizobacteria act as biostimulants in horticulture. Sci. Hortic. 2015, 196, 124-134. [CrossRef]

(C) 2016 by the authors; licensee MDPI, Basel, Switzerland. This article is an open access article distributed under the terms and conditions of the Creative Commons Attribution (CC-BY) license (http:/ / creativecommons.org/licenses/by/4.0/). 